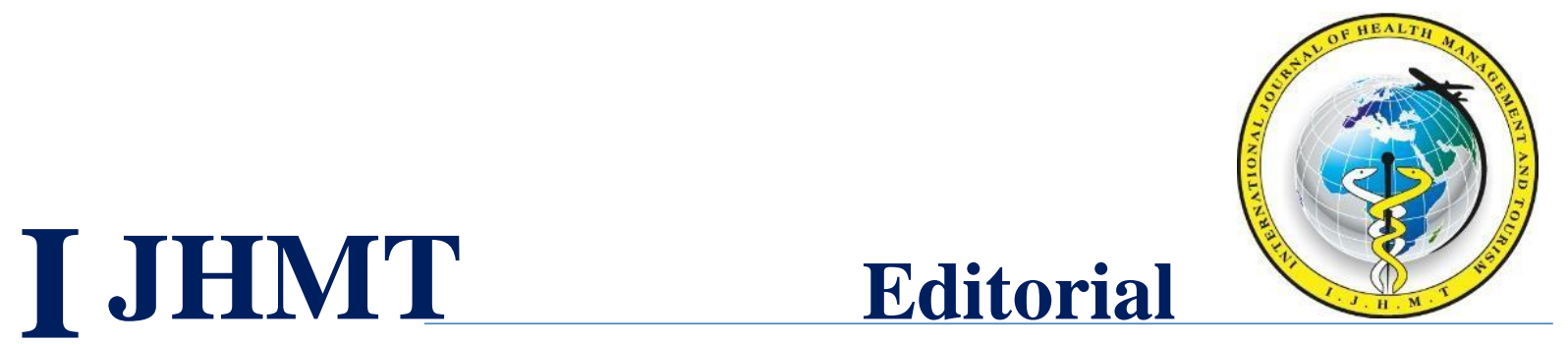

Internatıonal Journal Of Health Management And Tourism

\title{
CAN EMPLOYEE ASSISTANCE PROGRAM BE A SOLUTION FOR IMPROVINGWORKPLACE HEALTH? A CASE OF TURKEY
}

\author{
Tariq Mahmood FARMAN ${ }^{1}$ (D,Şule TUZLUKAYA ${ }^{2 *}$, Elif BODUROĞLU ${ }^{3}$ (D) \\ ${ }^{1}$ MBA, Specialist, Afghanistan tariq.farmaan@gmail.com \\ ORCID Number: 0000-0002-1854-7261 \\ 2*Assoc. Dr. Business Administration Department, Atılım University, Turkey sule.tuzlukaya@atilim.edu.tr \\ ORCID Number: 0000-0001-8244-6396 \\ ${ }^{3}$ Research Assist., Business Administration Department, Atılım University, Turkey \\ bodurogluelif@gmail.com \\ ORCID Number: 0000-0003-1132-7159 \\ Received: 22.01.2020 \\ Accepted: 29.04.2020 \\ Research Article
}

Abstract: This study aims to investigate the Employee Assistance Program (EAP) and its role in employee morale and productivity from the perspective of the managers. The data was collected through in-depth semi-structured interviews. In this study, the nature of the methodology is exploratory. Therefore, in the methodology, part researcher targeted to interview six people in charge of the Employee Assistance Program. The main objective is to understand the role of the Employee Assistance Program on Employees' "Morale and Productivity". On the other hand, there are higher chances of increasing productivity when employees have high morale. After the interviews, the opinions of managers were analyzed through NVIVO 12 program. The main findings indicate that EAP is critical for improving workplace health.

Keywords: Employee Assistance Program, employee morale, productivity, exploratory study, workplace health 


\section{Introduction}

In the last few years, there has been a dramatic increase in the integration of behavioral health into workplaces. The evidence from various studies in behavioral health, confirms the benefits of the Employee Assistance Program (EAP) on productivity (Merrick et al.2001; Azzone et al. 2009; Compton and McManus, 2015; Yu, Li and Hsu, 2009; Attridge, 2009). According to Shamasundar et al. (2016) organizations show a growing tendency of using EAP that supports counseling and consultation processes. EAP can be described as a free, confidential benefit that can assist employees with personal or work-related problems before they adversely affect their health or job performance (Yu, Li and Hsu, 2009).

According to the U.S. Department of Labor, Office of Disability Employment Policy (2014), Employee Assistance Programs (EAPs) are designed to benefit both employers and employees since it is a worksite-based program and resources. Employee Assistance Programs support companies and institutions to address productivity problems by supporting workers to recognize and solve individual problems that influence productivity. Within avoidance, classification, and analysis of such problems, Employee Assistance Programs counseling develop worker and work environment effectiveness and are a very important mechanism for maintaining and improving employees' well-being and productivity, sustaining valued workers, working to solve his/her issues, and recovering workers to operate after diseases or damages. Managers have discovered that active, prohibitive attempts to support workers recognize and solve individual problems before they have a severe family, medical, or work environment outcomes. According to Richard, William, and William (2009), an increase in work productivity can cause a decrease in work stress among employees and managers. It maintains employees to satisfy the demands of the employers. When a terrible incident attacks, it is convincing to understand that there is a scheme that can help workers. Employee Assistance Programs (EAP) are composed to present help for workers and find ways to life problems that might affect the capacity of employees to appear in a job and be productive in the job environment. EAP's are often provided confidential and provided to workers with no expense and accessibility to expert employees helps with a mixture of difficulties affecting workers. It might involve maintenance to employees who are suffering from individual difficulties like drug and alcohol abuse or distress, marriage and family challenges, and economic issues.

According to the World Health Organization (WHO), there are many benefits to achieving workplace health (Who, 2019). Workplace health is a combined result of employers and 
employees as well as society. Mainly it is related to the improvement of the health and wellbeing of employees. Workplace health is crucial for the sustainable growth of the organizations through an increasing number of happy, satisfied and engaged workers. Due to these programs, the work-personal life balance of the individuals can also be provided. When these are achieved in the workplace, employees are more effective and contribute to the success of the organization. Thus, the purpose of this research is to understand the Employee Assistance Program and its key elements as employee morale and productivity from the perspective of workplace health.

\section{Literature Review}

\subsection{Employee Morale}

According to Sarna (2016) employee morale is considered as vital in terms of the organization's performance. Morale is a group of feelings and attitudes which relate to mental and physical strength. Optimism, self-confidence, and a positive mental attitude are signs of morale in the workplace. Urban and Botez (2016) state that employees' morale has a great effect on organizations' success, performance, quality of products, quality of works, quality of services, and productivity. Low morale for longer periods may lead to illnesses like diabetes and heart disease and also poor decision making in the workplace. Low morale leads to (1) greater conflicts inside the companies, (2) absenteeism and turnover, (3) dissatisfaction, (4) employees' frustration, (5) decrease in productivity, and (6) lack of motivation inside the company. Thus, both physical and psychological wellbeing and health are highly related to workplace health. Sarna (2016) states that high morale can be considered as an important achievement of management and it is such a strong performance driver for the companies. It can be achieved after (1) eager teamwork among the employees, (2) commitment of employees inside the organization, (3) Finding the problem immediately and solving it, (4) organized and healthy workplace, (5) effective integrating inside the organization, (6) increased productivity, (7) high motivation (8) customer satisfaction.

\subsection{Employee productivity}

According to Shobe (2018) productivity is an important element of the business world. There are certain factors like the physical working environment, job satisfaction, management support and autonomy that can drive this important element at work. If the mental satisfaction of the employees is balanced, then it will lead to a comfortable mind, good spirits, motivation, high morale and higher productivity (Matin et al., 2014). Thus, there is a growing body of literature 
suggesting that worker health and productivity are related and that effective management of one will positively impact the other (Goetzel et al, 2007). Workplace Health Research Network (2017) states that the physical activity of employees is very important and it can increase employees' productivity, create a healthier workforce, and reduce the progress of costly diseases. Physically active employees are requiring fewer sick leaves, more productive, and have lower healthcare costs. This issue represents significant health and business cost.

\subsection{Relationship between EAP, morale, and productivity}

Employee Assistance Programs may provide support from at least three perspectives: leveraging the value of the organization's investment in their workforce; address the costs of doing business and mitigating the business risks. For all three areas, the vital focus of EAP can be determined as an improvement of the potential of the employees and the reduction of the negative behavioral health issues. Senthilnathan and Rukshani (2013) reveal that morale and productivity have a significant direct relationship. Employee turnover is causing productivity to decrease and it usually contributes to the low morale of the employee. Akintayo (2012) also states that there is a strong correlation between the workers' morale, perceived productivity and work environment. Consequently, managers are generally unaware of the costs associated with other programs and are seldom able to estimate total health and related lost productivity costs for the organization (Goetzel et al.2007). Employee Assistance Programs are considered a vital human resource management tool in contemporary businesses. Most of the employees experience health problems that are related to both mental and physical reasons.

In today's business world, companies are playing a crucial role in creating a modern world that we are living in today. These companies or organizations are made of lots of elements but employees can be addressed as key elements for every company. Sometimes, these employees face different types of problems that cause a company not to have their ideal work environment. Employee Assistance Program tends to prevent/solve the problems of their employee clients. This way employee feels valued. It supports employees to gain their health and energy back to continue the job productively.

\section{Methodology}

This study utilizes an exploratory research method with a qualitative approach. The goal is to reveal the relation of the EAP with morale and productivity with consideration of workplace health. According to Saunders, Lewis, and Thornhill (2009), exploratory research is an important 
nature for finding what is happening and to find a new vision or insight. It is about asking questions and assessing things in a new way. It can be very beneficial if you can present your understanding of the issue, especially if you are not sure about the nature of the problem. Neuman (2014) states that exploratory studies hardly present definitive answers it is mostly being addressed with "what" question. Detailed information about the structure of the questions can be found in Table 1 .

Table 1: Relation of Research Questions with Interview Questions

\begin{tabular}{|c|c|}
\hline Research Questions & Interview Questions \\
\hline $\begin{array}{l}\text { 1. What managers experience about } \\
\text { the Employee Assistance Program in } \\
\text { terms of employee morale? }\end{array}$ & $\begin{array}{l}\text { - What is the purpose of the Employee Assistance Program? } \\
\text { - What are the characteristics of employees with a morale problem? } \\
\text { - Why do you think that employees with morale problems should access to } \\
\text { Employee Assistance Program? } \\
\text { - How does Employee Assistance Program improve employees' morale? } \\
\text { - What amount of counseling is needed for employees to rid of morale problems? }\end{array}$ \\
\hline $\begin{array}{l}\text { 2: What managers experience about } \\
\text { Employee Assistance Program in } \\
\text { terms of productivity? }\end{array}$ & $\begin{array}{l}\text { - What is the purpose of Employee Assistance Program? } \\
\text { - What are the reasons that employees face a lack of productivity in their } \\
\text { company? } \\
\text { - How does EAP improve productivity within the work environment? } \\
\text { - What are the special challenges that companies face after losing their } \\
\text { employees' productivity? } \\
\text { - Why are you suggesting Employee Assistance Program for companies? }\end{array}$ \\
\hline $\begin{array}{l}\text { 3: What are managers' opinions } \\
\text { about Employee Assistance } \\
\text { Program's general issues (EAP } \\
\text { success, EAP participation, and } \\
\text { challenges encountered by EAP } \\
\text { experts)? }\end{array}$ & $\begin{array}{l}\text { - How EAP can be successful? } \\
\text { - How employees participate in EAP program? } \\
\text { - What challenges are encountered by experts who are in charge of Employee } \\
\text { Assistance Program? }\end{array}$ \\
\hline
\end{tabular}

\subsection{Participants}

The universe of this study covers the HRM and EAP managers in companies implementing the EAP system. Since the study proposes to investigate the relationships between EAP and workplace health through the perspective of managers, the participants have been chosen purposively among HRM and Employee Assistance Managers. Saunders, et al. (2009) stated 
that purposive sampling allows the researcher to use such judgments to select cases that will enable them to answer the research questions. In this study, based on two criteria the participants were selected; first, participants were expected to be HRM or Employee Assistance Managers, and second, all participants should be knowledgeable regarding the EAP program and its applications. All the selected managers have experience in terms of EAP. One of the researchers is related to the field of $\mathrm{HR}$, and through his social network, the other participants were contacted.

Table 2 demonstrates the general information about the participants. The researcher keeps anonymity and confidentiality in this research by using pseudonyms for participants.

Table 2: Information about participants

\begin{tabular}{lllc}
\hline Participants & Profession & Company Information & Years of Experiences \\
\hline $\begin{array}{l}\text { Participant 1 } \\
\text { (Pelin Bakar) }\end{array}$ & Responsible for & External EAP company & 8 months \\
After-Sales Services & - Firm-1 & \\
(Asli Ecem) & Human Resources & External EAP company & 1 year \\
Participant 3 & Senior Expert & - Firm-1 & \\
(Meral Dogan) & Human Resources & External EAP company & 11 months \\
$\begin{array}{l}\text { Participant 4 } \\
\text { (Zehra Bice) }\end{array}$ & Employee Assistance & External EAP company & \\
Participant 5 & Manager & - Firm-1 & 2 Years \\
(Erdem Gozdem) & Employee Assistance & Manufacturing & \\
& Manager & Company - Firm-2 & 4 years \\
$\begin{array}{l}\text { Participant 6 } \\
\text { (Nil Dilan) }\end{array}$ & Employee Assistance & External EAP company & \\
& Manager & - Firm-1 & year \\
\hline
\end{tabular}

\subsection{Data Collection}

In this study, the data is collected through open-ended and semi-structured interviews. Participants consent to share their opinions. Each session lasted around thirty minutes and taperecorded with permission. The selected six managers had experienced about the EAP program. The interview questions were developed according to the purpose of the study and the related literature. For face and content validity, three experts from the field examined the questions before the interviews are conducted in the field. 


\subsection{Data Analysis}

The collected data was turned into transcription after the interviews are finalized. All interviews and transcripts were analyzed by Nvivo Plus 11 Trial-Version. Qualitative data analysis is applied and the transcribed data was evaluated by descriptive content analysis. The main categories for the themes were determined according to research questions. These themes were categorized as "the purpose of EAP and success criteria", "EAP requirements for employees with morale problems", "the effect of EAP on morale and consulting period for morale problems", "employees productivity problems", "the effect of EAP on employees' productivity" and "productivity challenges".

\section{Findings}

The findings are organized based on the above-mentioned categories. Below each category, the related themes are provided.

\subsection{The purpose of EAP}

The purpose of EAP is considered as one of the main codes. According to the analysis of the transcripts, this main code is divided into three sub-codes as solving employee problems, performance, and productivity. These three sub-codes are followed by EAP managers' ideas during the interview. People in charge of the EAP participated and stated that this program aims to solve the problems of the employees and to provide healthier work environments. Managers are mostly indicating that the EAP provides a high level of productivity since employees can work happily, with high levels of morale. The negative factors of low morale are also stated by the managers as they can be related to the feeling of insecurity, uncertain business conditions, lack of fair compensation policy, and excessive outsourcing practices. These factors also affect employees negatively.

\subsection{EAP's success criteria}

Employee Assistance Program should surpass some of the good qualities to become successful. According to the managers, the EAP success can occur if it focuses on both the prioritization of conditions and the reliability of EAP Service. Reliability of EAP service and prioritization of conditions and requirements while applying Employee Assistance Program should consider the program's characteristics, provided services, employee's characteristics, and features of country and region. Also, for the reliability of the Employee Assistance Program the employees' information should be kept confidential. According to EASNA (2015), the success of the 
Employee Assistance Program is the ability to provide a free of charge confidential assistance service whenever it is necessary. It was suggested that the given counseling should be from correct and reliable sources, the promised services should be on time without interruption. In this study, it has been observed that the literature supports this research's findings and the success of EAP depends on the environment and reliability of EAP.

\subsection{Characteristics of employees with a morale problem}

According to EAP managers, employees who are suffering from moral issues they are usually aggressive, angry, low energy, loss of motivation, impatient, and stressed. These characteristics help managers to recognize the existence of moral problems among the employees. These also reflect on the health of employees, negatively. It was observed that employees with morale problems are facing concentrating on their work, and low morale causes them to lose motivation. While having psychological assistance they are expecting to be healed at a short amount of time and reflecting their personnel problems to their professional life. According to Urban and Botez (2016) researching and developing employee's morale helps the organization to become more successful. In this study, the literature supports the findings of this research indirectly. Loss of motivation, impatient, and low energy are the characteristics of employees with morale problems. However, EAP causes employees to increase their positive attitude and productivity.

\subsection{EAP Requirements for Employees with Morale Problems}

Employees who are suffering from morale problems should be willing to seek assistance, especially for their psychological health. Reaching to the right source and expert on time, seeking solutions to the problems and opportunity for psychological support are the three requirements that help EAP to improve morale. According to the analysis, employees with morale problems need to meet the right source at the right time. The employees with morale problems can have the opportunity to get assistance under the three themes. Experts are taking employees with morale problems to achieve reaching to the right source and expert on time, seeking solutions to the problems, opportunity for psychological support. According to Elder, Agee, and Adamson (2018) counselors play an essential employee supporting role, especially in terms of stress. Employee Assistance Program managers provide counseling to solve employees' stress, loss of confidence, and burnout which can be named as serious workplace health issues. Managers usually encourage employees to seek counseling whenever they experience a problem. These all depend on the support of EAP managers and the quality of engagement. 


\subsection{The effect of EAP on morale}

According to the analysis, it was observed that EAP results in a positive impact and getting a quick solution. The experts mentioned that morale problems can be improved very quickly, and it may affect the work potential of the employees positively. According to Bophela and Govender (2015), Employee Assistance Program is essential in terms of addressing job-related stress. Job-related stress is the main reason for low productivity, morale, health, and human error.

\subsection{Consulting Period for Morale Problems}

Employees with morale problems usually need more than a session. Therefore, as EAP managers claim during the interview, at least three sessions needed for employees with morale problems since each consulting period happens once a week. Although the amounts can be changed according to the severity of the problem that an employee faces. After the interviews, it was observed that the consulting period for morale problems shows different views. But it has been mentioned that 5-6 sessions of interviews have a positive impact on employees. Also, after the meeting and recognizing the problems, the final visiting period is getting determined. Ekpang (2015) claims that Employee Assistance Program managers should set a clear policy, organizational assistance, and willingness to solve the problem in the organization. Whenever employees in the organization face performance problems, it is important to solve the problem as soon as possible. When problems last longer, it becomes more difficult to gain a satisfactory solution. In this study, the literature differs from the findings of this category. The literature emphasizes on solving the problem as soon as possible. On the other hand, managers who are interviewed are claiming that 6-8 sessions are considered enough and each session happens once a week. For instance, participant 1 stated "The first session includes the introduction of employees. The second session ends up figuring the problem out, how much time it will take, and how it will be solved. At least three sessions are needed for solving the problem because each session happens once a week. Three weeks can happen but the recommended amounts of sessions are at least five weeks and it is important according to psychological assistance."

\subsection{Employees Productivity Problems}

There are numerous reasons for productivity problems. EAP managers during the interview expressed several reasons like personnel problems, professional education, and qualification, low wage, organizational communication and compliance, and organization culture. Solving these 
problems can positively affect productivity. According to the findings, the following points like personnel problems, professional education, and qualification, organizational communication, and compliance, organization culture, low wages' effects were experienced. EAP experts indicate that under personnel problems family and personnel life problems are the factors for decreasing productivity and lack of professional education and qualification causes low productivity. Besides this, inside the company relationship with managers and their colleagues in organizational communication and compliance, organization culture has its effects on productivity. On the other hand, when the employees do not get sufficient wages after their efforts, this will cause the employees to face with lack of productivity. According to EASNA (2015), Employee Assistance Program managers help organizations. They assist employees and their family in terms of personal problems, and other problems like health, family, financial, legal, and emotional and other problems that may negatively impact on performance and productivity of employees.

\subsection{The Effect of EAP on Employees Productivity}

The good quality of the EAP is that it makes the employees focus on their work. When employees know that there's an external guide and they can benefit from it. This helps them to concentrate more on their work. During the interviews, EAP managers claim that when employees get a solution to their problem, directly their productivity increases, so their health does as well. After the interviews, the EAP experts have the same opinion on the effect of EAP on employees' productivity. According to these interviews, experts claim that employees after using EAP services concentrate on their job, solving the problem, and of course, it causes employees to have a positive impact on their productivity development affects. According to Masi (2011), the Employee Assistance Program is designed to help employees in two ways (1) addressing and solving organizations' productivity (2) solving the personal problems including but not limited to problems like health, family, financial, legal, and emotional problems.

\subsection{Challenges on Lack of Productivity}

When employees are suffering from a lack of productivity, things do not end that way. It is very important to solve productivity problems among the employees, otherwise, productivity problems lead the employees to certain other problems like facing absenteeism, low productivity, decreasing the quality of work, organizational problems, and problems in time management. According to findings, low productivity among the employees that were explained by managers 
is worker absenteeism, low productivity, a decrease in work quality, organizational problems, and problems in time management. Accordingly, managers also claim that points on lack of productivity are coming late to work. This problem causes a reduction of work performance, reducing the quality, causing a problem inside the organization and facing problems in time management have been examined. According to EASNA (2015) employees' lack of productivity can be caused due to substance issues, untreated health problems, poor customer relationships, absenteeism, lack of work quality, morale problems, and turnover. Employee Assistance Program reduces the costs that are caused by absenteeism, productivity, performance and turnover (Joseph and Walker, 2017).

\section{Discussion and Conclusion}

Employee Assistance Program required considering morale and productivity themes from the perspectives of employee and workplace health. In line with this, researches on that particular field have the utmost importance. Although there have been several studies on EAP, the need for exploratory studies is obvious for detecting the topic in more detail.

This study focuses on the Employee Assistance Program from the perspectives of employee morale and productivity. The majority of researches address employee morale and productivity as important elements. Lack of these elements leads employees to face problems according to professional life, especially in terms of productivity. The reviewed studies found that this program aims to solve the problems of the employees and to increase their performance and productivity. In general, the results revealed that the EAP has a high level of importance in terms of increasing the productivity of the employees due to high levels of morale. It was observed that employees with morale problems are facing concentrating on their work, and low morale causes them to lose motivation. While having psychological assistance they are expecting to be healed at a short amount of time and reflecting their personnel problems to their professional life. In conclusion, the current study generally supports that moral problems can be improved very quickly and as a result, it will affect the work potential of the employees positively. This study also supports that employees after using EAP services concentrate on their job, solve their problems. Also, EAP causes employees to have a positive impact on their product development. Additionally, some boundaries for buying or providing the best possible Employee Assistance Services are also determined as a result of the study. Such boundaries present opportunities for development in the upcoming years to progress the structure, coordination, and integration of Employee Assistance Programs. Employee Assistance Program is a type of program that 
increases the capabilities of employees. Another contribution of the study is to reveal the importance of focusing on the capability of an employee.

While conducting the interviews due to the shortage of time, it was tried to be as efficient as possible. Due to the limitation of the number of participants and time, the interviews were tried to be conducted as effectively as possible.

According to the findings of this research, it is possible to recommend practical and theoretical applications. First of all, EAP managers should improve productivity among the workers by raising their salary. This will boost the employee's morale and can create loyalty. Second, the EAP can employ promotions to increase productivity. On the other side, the researchers should consider the other dimensions of the EAP, such as financial and legal solutions. The structure of this research contains the opinions of people in charge of the Employee Assistance Program in companies that are located in Turkey.

\section{References}

Akintayo, D. (2012). Working environment, workers' morale and perceived productivity in industrial organizations in Nigeria. Education Research Journal, 2, 87-93.

Attridge, M. (2009). Employee assistance programs: A research-based primer. The handbook of work and health psychology, 383-407.

Azzone, V., McCann, B., Merrick, E. L., Hiatt, D., Hodgkin, D., \& Horgan, C. (2009). Workplace stress, organizational factors, and EAP utilization. Journal of Workplace Behavioral Health, 24(3), 344-356.

Bophela, N. R., \& Govender, P. (2015). Employee Assistance Programmes (Eaps) And Quality Of Work Life In A Public Sector Organization: Biographical Influences. Corporate Ownership and Control,12(3). doi:10.22495/cocv12i3c2p4

Compton, R.L. and McManus, J.G., 2015. Employee assistance programs in Australia: Evaluating success. Journal of Workplace Behavioral Health, 30(1-2), pp.32-45.

Ekpang, U, P. (2015) Counselling For Effective Work Performance: A Way for Service Improvement. IOSR Journal Of Humanities And Social Science. 20, 3, 39-43.

Elder, L, R., Agee, M., \& Adamson, C. (2018). Workplace counseling and the contemporary world of work. New Zealand Journal of Counselling. 38, 1, 54-67.

Goetzel, R. Z., Shechter, D., Ozminkowski, R. J., Stapleton, D. C., Lapin, P. J., McGinnis, J. M., ... \& Breslow, L. (2007). Can health promotion programs save Medicare money?. Clinical Interventions in Aging, 2(1), 117.

Joseph, B., \& Walker, A. (2017). Employee assistance programs in Australia: The perspectives of organisational leaders across sectors. Asia Pacific Journal of Human Resources, 55(2), 177191. 
Kipkemoi, C, A., Omolo, W, J., \& Onditi, L, A. (2016) Influence of Employee Assistance Programs on Employee Performance in Mumias Sugar Company, Kenya. Developing Country Studies. 6,2, 169-172.

Masi, D. A. (2011). Correct Understanding and Application of EAP Necessary for All Entities that Implement Measures for Mental Health. Tokyo, Japan.

Matin, H, Z., Razavi, H, R., \& Emamgholizadeh, S. (2014) Is stress management related to workforce productivity? Iranian Journal of Management Studies 7: 1-19.

Merrick, E. L., Hodgkin, D., Hiatt, D., Horgan, C. M., \& McCann, B. (2011). EAP service use in a managed behavioral health care organization: from the employee perspective. Journal of workplace behavioral health, 26(2), 85-96.

Neuman, W. L. (2014). Social research methods: Qualitative and Quantitative approaches. Boston: Allyn and Bacon.

Neuman, W. L. (2014). Social research methods: Qualitative and Quantitative approaches. Boston: Allyn and Bacon.

Saunders, M., Lewis, P., \& Thornhill, A. (2009) Research methods for business student. Published by Rotolito Lombarda, Italy.

Shamasundar, C. Bhola, P. \& Raguram, A. (2016). Ethical Issues in Counseling and Psychotherapy Practice: Employee Assistance Programmes: Emergent Ethical Issues. Published by Springer Nature \& Business Media Singapore Pte Ltd.

Sarna, S. K. (2016) Ispat Guru, Retrieved From http://ispatguru.com/employee-morale/

Shobe, K. (2018). Productivity driven by job satisfaction, physical work environment, management support and job autonomy. Business and Economics Journal, 9, 1-4.

Senthilnathan, S., \& Rukshani, K. (2013). A review on the relationship variables to employee morale and organizational trust. International Journal of Innovative Research and Practices, 1 , $8-12$.

Urban, V., \& Botez, N. (2016). The Importance of Analysing the Employees' Mood. Economy Transdisciplinarity Cognition 19(1): 40-45.

WHRN, Workplace Health Research Network. (2017). Physical activity in the workplace a guide for employers. Published by John Hopkins Bloomberg school of public health

Yu, M.C., Lin, C.C. and Hsu, S.Y., 2009. Stressors and burnout: The role of employee assistance programs and self-efficacy. Social Behavior and Personality: an international journal, 37(3), pp.365-377. 